Check for updates

Cite this: RSC Adv., 2017, 7, 25429

\title{
The influence of deposited potential on the ORR activity of Pt catalysts on glassy carbon electrode
}

\author{
Fengting Cao, ${ }^{a}$ Zhao Zang, ${ }^{b}$ Shimei Sun, ${ }^{a}$ Xiaolin Sun, ${ }^{a}$ Xichao Li, ${ }^{a}$ Tao Liu (D) ${ }^{a}$ \\ and Jianfei Wu (D)*a
}

In this study, Pt catalysts were fabricated on a glassy carbon (GC) electrode Pt/GC using a potentiostatic technique at different reduction potentials in potassium hexachloroplatinate solutions with hydrochloric acid. The compositions of the catalysts were determined using energy dispersive spectroscopy (EDS), the surface morphologies were observed using scanning electron microscopy (SEM), and the crystal structure was confirmed using thin-film X-ray diffraction (XRD). The results show that all the electrodeposited Pt/GC catalysts exhibit a higher electrochemical activity for the oxygen reduction reaction (ORR) when compared with a commercial Pt/C electrode. There is an optimum electrodeposited potential $(-0.15 \mathrm{~V} v \mathrm{~s}$. $\mathrm{Ag} / \mathrm{AgCl})$ at which the Pt/GC electrode displays the highest electrochemical activity for the ORR due to the high-index plane and shape effect of the Pt particles. At a lower electrodeposited potential, the applied current density is high enough to form large and coarse metal particles, while at a higher electrodeposited potential, the active sites of Pt particles decrease because of its equiaxed shape.

Received 27th February 2017 Accepted 20th April 2017

DOI: 10.1039/c7ra02444d

rsc.li/rsc-advances
Although electrodeposition is an attractive technique to prepare the catalyst layers for PEMFC, little work has been carried out on the preparation of catalysts using this method. The performance of Pt nanoparticles prepared using potentiostatic deposition is determined by several parameters, such as deposited potential, deposition temperature and the amount of charge passed during the deposition process. Yun-Bin Cho et $a .^{18}$ fabricated nanoporous $\mathrm{Pt}$ films with three different degrees of porosity using amperometry and cyclic voltammetry. Among these, the one prepared by applying $-0.21 \mathrm{~V}$ ( $v s$. SCE) for $1300( \pm 100) \mathrm{s}$ had the smallest particle size and exhibited the most positive ORR onset potential in the kinetically controlled region. Their study indicated the influence of the electrodeposition potential on the structure of the Pt nanoparticles and the kinetics of the ORR reaction. Nguyet Doan et al. ${ }^{19}$ obtained mesoporous Pt using the potentiostatic mode at $-175 \mathrm{mV} v s$. SCE, and the mass activities were better than those of other Pt catalysts reported in the literature. Nevertheless, the reason for choosing this deposition potential in their study was not elaborated on, and it is uncertain whether this potential was optimal or not. Zaenal Awaludin et al. ${ }^{20}$ also prepared a Pt/GC catalyst using the potentiostatic deposition method. The deposited potential was fixed at $-0.06 \mathrm{~V}$ vs. $\mathrm{Ag}|\mathrm{AgCl}| \mathrm{KCl}(\mathrm{sat})$, and the amount of charge passed during the deposition was set at $32 \mathrm{mC} \mathrm{cm}^{-2}$. Unfortunately, a clear explanation of the deposition potential was also not given in their report.

Based on the analysis of the literature thus far, it can be seen that the optimal deposition potentials of Pt particles are not identical and vary with the specific deposition conditions. A systematic investigation of this issue is lacking. For this reason,
${ }^{a}$ Qingdao Industrial Energy Storage Research Institute, Qingdao Institute of Bioenergy and Bioprocess Technology, Chinese Academy of Sciences, No. 189 Songling Road, 266101 Qingdao, PR China. E-mail: wujf@qibebt.ac.cn; Tel: +86-0532-80662751

${ }^{b}$ College of Mechanical and Electrical Engineering in China University of Petroleum, Qingdao, 266580, PR China 
the aim of the present study was to find out the optimal deposition potential of Pt particles on the glassy carbon electrode (Pt) GC) to achieve the highest ORR catalyst activity, and the relative mechanism was proposed.

\section{Experimental}

\subsection{Preparation of electrocatalysts}

The electrodeposition process was conducted in a threeelectrode cell using an electrochemical workstation (CHI750E). A glassy carbon electrode (GC) with a diameter of 3 $\mathrm{mm}$ was chosen as the substrate, and a Pt wire and $\mathrm{Ag} / \mathrm{AgCl}$ (in saturated $\mathrm{KCl}$ ) were used as the counter and the reference electrodes, respectively. The GC electrode was mechanically ground with silicon carbide papers from 3000 to 5000 grit, followed by ultrasonication in ethyl alcohol and Milli-Q water for $10 \mathrm{~min}$, sequentially. The electrolyte consisted of $3 \mathrm{mM}$ potassium hexachloroplatinate $\left(\mathrm{K}_{2} \mathrm{PtCl}_{6}\right)$ and $0.1 \mathrm{M}$ hydrochloric acid ( $\mathrm{HCl})$. A potential of $-0.20 \mathrm{~V},-0.15 \mathrm{~V}$ and $-0.06 \mathrm{~V}$ (vs. $\mathrm{Ag} / \mathrm{AgCl})$ was applied to the GC electrode in the electrolyte $\left(3 \mathrm{mM} \mathrm{K}_{2} \mathrm{PtCl}_{6}\right.$ $+0.1 \mathrm{M} \mathrm{HCl}$ ) under a saturated Ar environment, and the amount of charge during the deposition was set at $32 \mathrm{mC} \mathrm{cm}^{-2}$.

For comparison, a commercial $\mathrm{Pt} / \mathrm{C}$ thin film catalyst was prepared by adopting a technique based on the report of Garsany et al. ${ }^{21}$ Briefly, a 67\% isopropanol solution (marked solution A) was acquired by mixing $18 \mathrm{~mL}$ of isopropanol and $9 \mathrm{~mL}$ of pure water. Furthermore, $21 \mathrm{~mL}$ of solution A was transferred into a vial containing $34.5 \mathrm{mg}$ of 40 (wt\%) commercial Pt/C (JM, Johnson Matthey Corp.), followed by ultrasonication for $60 \mathrm{~min}$; thus solution B was obtained. After that, $3.92 \mathrm{~mL}$ of solution A, $1.08 \mathrm{~mL}$ of solution B and $20 \mu \mathrm{L}$ of a 50 (wt\%) Nafion solution were mixed together and ultrasonicated for $30 \mathrm{~min}$; thus the commercial $\mathrm{Pt} / \mathrm{C}$ ink was prepared. Finally, $5 \mathrm{~mL}$ of the prepared commercial Pt/C ink was cast onto a bare GC disk electrode $(\Phi 3 \mathrm{~mm})$ and dried in air. The prepared commercial $\mathrm{Pt} / \mathrm{C}$ electrode had a Pt loading of $10 \mathrm{mg}_{\mathrm{Pt}} \mathrm{cm}^{-2}$.

\subsection{Electrochemical measurements}

Cyclic voltammetry (CV) was conducted in $0.1 \mathrm{M} \mathrm{HClO}_{4}$ under a saturated $\mathrm{N}_{2}$ and $\mathrm{O}_{2}$ environment at a scan rate of $200 \mathrm{mV} \mathrm{s}^{-1}$. The electrochemical surface area (ECSA, in $\mathrm{m}^{2} \mathrm{~g}_{\mathrm{Pt}}{ }^{-1}$ ) of Pt was assessed by integrating the hydrogen desorption region obtained in the CV measurements under a saturated $\mathrm{N}_{2}$ atmosphere. The electrochemical impedance spectroscopy (EIS) of Pt/GC was obtained under a saturated $\mathrm{O}_{2}$ environment at an open circuit potential (OCP) to evaluate the impedance of the catalysts. The frequency ranged from $10 \mathrm{kHz}$ to $10 \mathrm{mHz}$ with an amplitude of $5 \mathrm{mV}$ AC signals, and the ZSimpDemo 3.30d software was used to fit the EIS data. These electrochemical measurements were also conducted using the electrochemical workstation (CHI750E) mentioned above.

All reagents used in this study were analytical-grade; oxygen and nitrogen were $99.9 \%$ pure provided by a local supplier. All electrochemical measurements were conducted at least twice for repeatability at room temperature around $25 \pm 1{ }^{\circ} \mathrm{C}$. The potential values in this study were versus $\mathrm{Ag} / \mathrm{AgCl}$ (in saturated $\mathrm{KCl})$ unless noted otherwise.

\subsection{Materials characterization}

In order to facilitate the surface observations, indium tin oxide (ITO) conductive glass was chosen as the substitute of the GC electrode when preparing the corresponding specimens. In the process of electrodeposition on ITO, the amount of charge passed was the same to that on the GC electrode $\left(32 \mathrm{mC} \mathrm{cm}^{-2}\right)$.

The surface morphology and energy dispersive spectra (EDS) of the as-prepared Pt/ITO electrodes were observed using a Hitachi S-4800 field emission scanning electron microscope (SEM), and the crystal structure was confirmed using thin-film X-ray diffraction (XRD) (Rigaku D/MAX-2500) equipped with a $\mathrm{Cu} \mathrm{K} \alpha$ radiation source. XRD analysis was carried out using a Rigaku X-ray diffractometer with a $\mathrm{Cu} \mathrm{K} \alpha(\lambda=0.15418 \mathrm{~nm})$ radiation source and a Ni filter.

\section{Results and discussion}

\subsection{Electrochemical properties}

Fig. 1(a) shows the amperometric $i-t$ curves measured during the electrodeposition of Pt/GC at different potentials. It can be seen that the deposition current density first increased rapidly and then achieved a steady platform value under all the
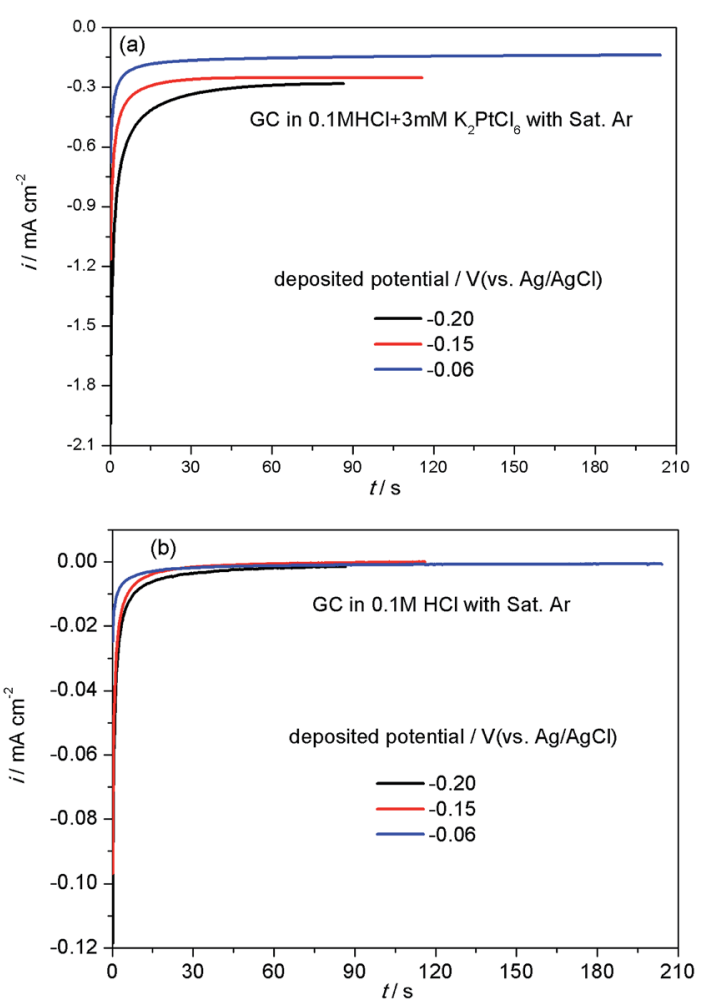

Fig. 1 The $i-t$ curves for the electrodeposition process obtained at different deposited potentials in Ar-saturated $0.1 \mathrm{M} \mathrm{HCl}$ solution with (a) and without (b) $3 \mathrm{mM} \mathrm{K}_{2} \mathrm{PtCl}_{6}$. Time to reach the set amount of charge $\left(32 \mathrm{mC} \mathrm{cm}^{-2}\right)$ : $87 \mathrm{~s}$ at $-0.20 \mathrm{~V} ; 116 \mathrm{~s}$ at $-0.15 \mathrm{~V} ; 204 \mathrm{~s}$ at $-0.06 \mathrm{~V}$. 
deposition potentials studied. The platform value of current density decreased with an increase in the deposition potential, leading to the times of reaching the set amount of charge (32 $\mathrm{mC} \mathrm{cm}{ }^{-2}$ ) to prolonged, which were 87,116 and $204 \mathrm{~s}$ at -0.20 , -0.15 and $-0.06 \mathrm{~V}$, respectively. It is reported ${ }^{22}$ that the reduction of $\mathrm{PtCl}_{6}{ }^{2-}$ to $\mathrm{Pt}^{2+}$ species should occur at potentials more positive than $-0.3 \mathrm{~V}_{\mathrm{MSE}}(0.119 \mathrm{~V} v s$. $\mathrm{Ag} / \mathrm{AgCl})$ when the hydrogen evolution is negligible at $-0.5 \mathrm{~V}_{\mathrm{MSE}}(-0.081 \mathrm{~V} v s$. $\mathrm{Ag} /$ $\mathrm{AgCl}$ ) and a current efficiency close to $100 \%$ is expected. Accordingly, under these three deposition potentials of -0.20 , -0.15 and $-0.06 \mathrm{~V}, \mathrm{PtCl}_{6}{ }^{2-}$ can be readily reduced into $\mathrm{Pt}^{2+}$ species.

In the electrodeposition process of $\mathrm{Pt} / \mathrm{GC}$, the total quantity of charge $\left(Q_{\text {tot }}, 32 \mathrm{mC} \mathrm{cm}^{-2}\right)$ was divided into two parts: one part of the charge was consumed by the reduction of $\mathrm{PtCl}_{6}{ }^{2-}$ into Pt $\left(Q_{\mathrm{Pt}}\right.$, in $\left.\mathrm{mC} \mathrm{cm}^{-2}\right)$ and the other part was used for the double layer charging $\left(Q_{\mathrm{dl}}\right.$, in $\left.\mathrm{mC} \mathrm{cm}^{-2}\right)$. $Q_{\mathrm{dl}}$ could be obtained by integration of the amperometric $i-t$ curves in $0.1 \mathrm{M} \mathrm{HCl}$ solution at three deposited potentials $(-0.20,-0.15$ and $-0.06 \mathrm{~V})$, as seen in Fig. 1(b). At each potential, the deposition time was set the same as with that used in the deposition solution with $3 \mathrm{mM}$ $\mathrm{K}_{2} \mathrm{PtCl}_{6}$. The Pt loading amount of the Pt/GC catalysts ( $W$ in $\mu \mathrm{g}$ $\mathrm{cm}^{-2}$ ) was calculated by the quantity of electricity related to the total reduction of $\mathrm{PtCl}_{6}{ }^{2-}$ into $\mathrm{Pt} Q_{\mathrm{Pt}}$ using the following equation: ${ }^{23}$

$$
W=\frac{M Q_{\mathrm{Pt}}}{z F} \times 10^{3}
$$

where $M$ is the atomic weight of $\mathrm{Pt}\left(195.1 \mathrm{~g} \mathrm{~mol}^{-1}\right), z$ the number of exchanged electrons (4) and $F$ is the faradaic constant (96 500 $\mathrm{C} \mathrm{mol}^{-1}$ ). The results for $Q_{\mathrm{tot}}, Q_{\mathrm{dl}}, Q_{\mathrm{Pt}}$ and $W$ are listed in Table 1. As can be seen, the Pt loadings of $\mathrm{Pt} / \mathrm{GC}$ at all the deposition potentials studied are close to each other, around $16 \mu \mathrm{g} \mathrm{cm}{ }^{-2}$.

The CV curves obtained for bare GC, commercial Pt/C electrode and the as-prepared Pt/GC catalysts under a saturated $\mathrm{Ar}$ atmosphere are shown in Fig. 2(a). There was no peak at the bare GC electrode, implying that no electrochemical reaction occurred in this case. For a better comparison, the catalytic activity of Pt was normalized and calculated in units of $\mathrm{Ag}_{\mathrm{Pt}}{ }^{-1}$, as shown in Fig. 2(b). It can be seen that an unobvious reduction peak emerged in the range of $0.5-0.6 \mathrm{~V}$. The explanation of this peak is that the Pt atom was oxidized at the high initial scan potential (1.0 v) and then reduced when the potential shifted to the lower region. On the other hand, the hydrogen desorption area enlarged with an increase in the deposition potential. It is known ${ }^{24}$ that the ECSA of Pt can be determined by dividing the electric charge for hydrogen desorption $Q_{\mathrm{H}}(\mathrm{C})$ by the standard charge of hydrogen on a smooth Pt surface $Q_{\mathrm{H}-\mathrm{Pt}}\left(\right.$ i.e., $\left.2.10 \mathrm{C} \mathrm{m}^{-2}\right):{ }^{20}$
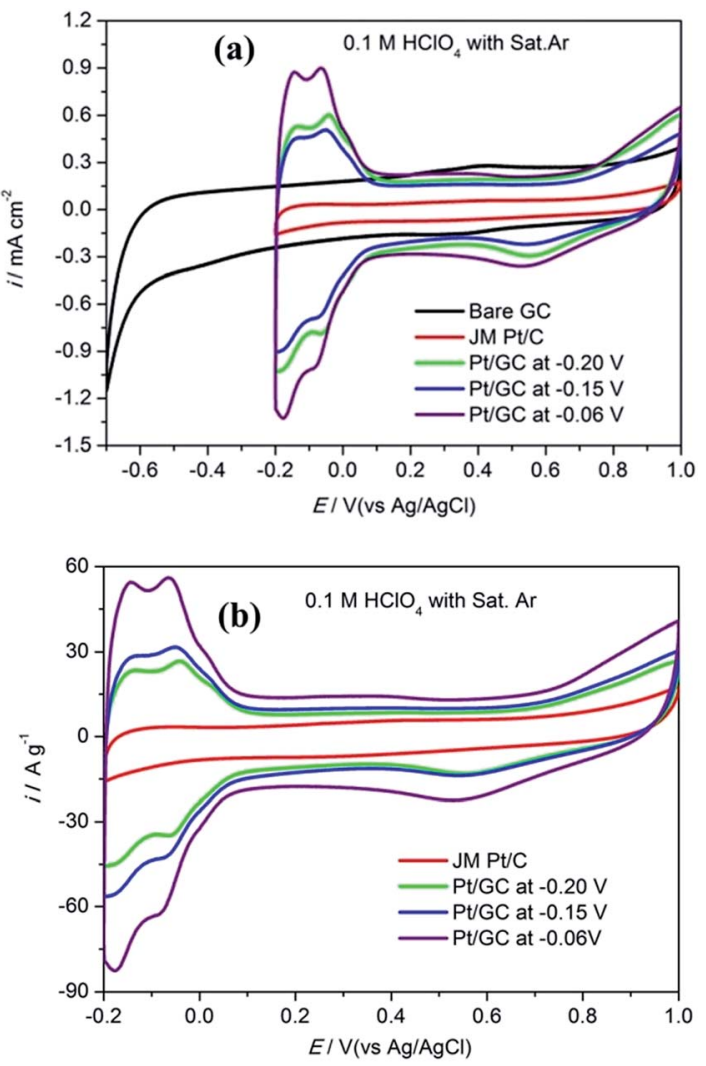

Fig. 2 The cyclic voltammogram curves in unit of $\mathrm{mA} \mathrm{cm}^{-2}$ (a) and $A$ $\mathrm{g}^{-1}$ (b) obtained for a commercial Pt/C electrode and the as-prepared $\mathrm{Pt} / \mathrm{GC}$ catalysts in $0.1 \mathrm{M} \mathrm{HClO}_{4}$ under a saturated $\mathrm{Ar}$ atmosphere.

$$
\operatorname{ECSA}\left(\mathrm{m}^{2} \mathrm{~g}_{\mathrm{Pt}}{ }^{-1}\right)=\frac{Q_{\mathrm{H}}}{W A Q_{\mathrm{H}-\mathrm{Pt}}} \times 10^{6}
$$

where $W$ is Pt loading amount in the Pt/GC catalyst $\left(\mu \mathrm{g} \mathrm{cm}^{-2}\right)$ and $A$ is the geometric area of the disk GC electrode (i.e., $0.07065 \mathrm{~cm}^{2}$ ). The calculated results for the ECSA are also listed in Table 1. Accordingly, the ECSA increased with an increase in the deposition potential and had the largest value at $-0.06 \mathrm{~V}$. Nevertheless, the high ECSA of Pt does not accurately represent high ORR activity since the ORR activity is influenced by several factors including the ECSA but not limited to it. Other factors such as high electrical conductivity and an increased density of surface defects can also contribute to the ORR activity of the catalysts.

Fig. 3 shows the CV curves obtained for bare GC, the commercial Pt/C electrode and the as-prepared Pt/GC catalysts under a saturated $\mathrm{O}_{2}$ atmosphere. A notable reduction peak

\begin{tabular}{|c|c|c|c|c|c|}
\hline Deposited potential/V & $Q_{\text {tot }} / \mathrm{mC} \mathrm{cm}^{-2}$ & $Q_{\mathrm{dl}} / \mathrm{mC} \mathrm{cm}^{-2}$ & $Q_{\mathrm{Pt}} / \mathrm{mC} \mathrm{cm}^{-2}$ & $W / \mu \mathrm{g} \mathrm{cm} \mathrm{cm}^{-2}$ & $\mathrm{ECSA} /\left(\mathrm{m}^{2} \mathrm{~g}_{\mathrm{Pt}}{ }^{-1}\right)$ \\
\hline $\mathrm{JM} \mathrm{Pt} / \mathrm{C}$ & - & - & - & 10 & 0.033 \\
\hline-0.20 & 32 & 0.45 & 31.55 & 15.95 & 8.219 \\
\hline-0.06 & 32 & 0.29 & 31.71 & 16.03 & 17.80 \\
\hline
\end{tabular}

Table 1 The electrochemical characteristics of the JM Pt/C and the Pt/GC catalysts 

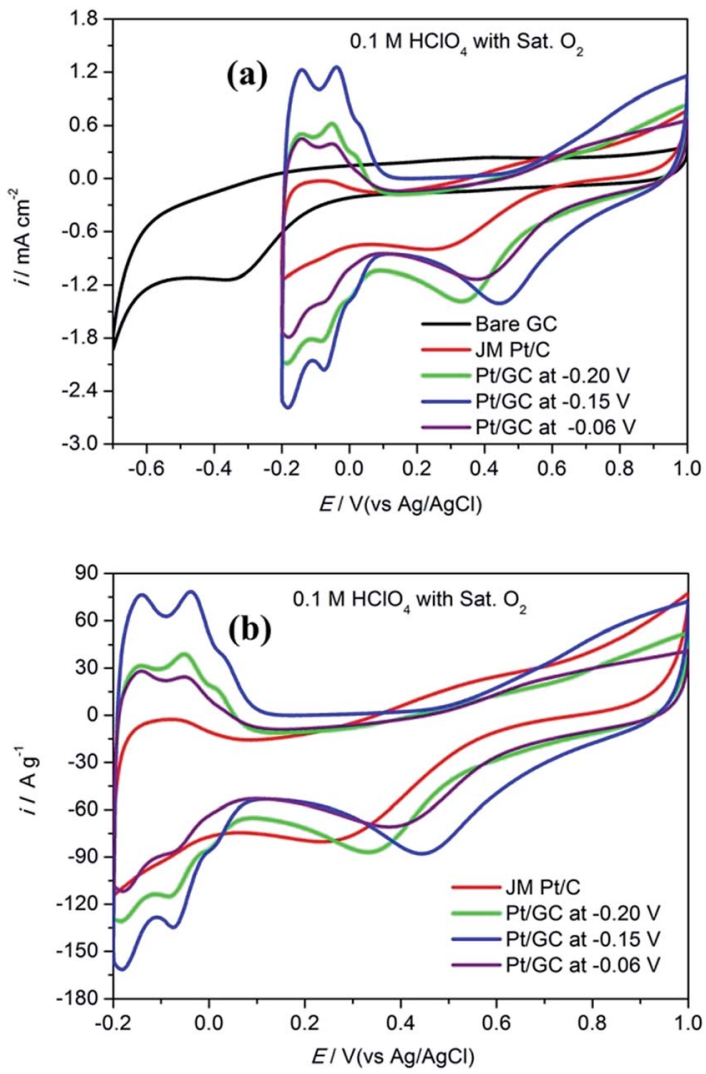

Fig. 3 The cyclic voltammogram curves in unit of $\mathrm{mA} \mathrm{cm}^{-2}$ (a) and $A$ $\mathrm{g}^{-1}$ (b) obtained for a commercial Pt/C electrode and the as-prepared $\mathrm{Pt} / \mathrm{GC}$ catalysts in $0.1 \mathrm{M} \mathrm{HClO}_{4}$ under saturated $\mathrm{O}_{2}$ atmosphere.

appeared in each CV curve that was not shown in those under a saturated $\mathrm{Ar}$ atmosphere shown in Fig. 2(a), and the current increased evidently because of the presence of $\mathrm{O}_{2}$. Evidently, this peak belongs to the oxygen reduction reaction (ORR). On the bare GC electrode surface, a reduction peak appeared at around $-0.30 \mathrm{~V}$ compared to that observed in an Ar atmosphere. In regard to the electrodeposited Pt/GC catalysis, the ORR peak potential shifted significantly towards a positive value. The specific ORR peak potentials of the commercial Pt/C and electrodeposited Pt/GC electrodes are shown in Table 2, as well as the difference ( $\left.\Delta E_{\text {shift }}\right)$ between the ORR peak potentials of the $\mathrm{Pt} / \mathrm{GC}$ electrodes and that of the commercial Pt/C electrode is exhibited. Clearly, the Pt/GC electrode prepared under $-0.15 \mathrm{~V}$ shifted by the maximum value, $0.210 \mathrm{~V}$. It is believed that a shift in the ORR peak to a higher potential reflects a decrease in the adsorption strength for the other oxygen

Table 2 The parameters obtained from the cyclic voltammograms shown in Fig. 3

\begin{tabular}{llll}
\hline Deposited potential $/ \mathrm{V}$ & $E_{\mathrm{p}, \mathrm{ORR}} / \mathrm{mV}$ & $\Delta E_{\text {shift }} / \mathrm{mV}$ & $i_{\mathrm{p}, \mathrm{ORR}} / \mathrm{mA} \mathrm{cm}^{-2}$ \\
\hline $\mathrm{JM} \mathrm{Pt} / \mathrm{C}$ & 0.236 & 0 & -0.803 \\
-0.20 & 0.332 & 0.096 & -1.386 \\
-0.15 & 0.446 & 0.210 & -1.407 \\
-0.06 & 0.375 & 0.139 & -1.135
\end{tabular}

containing species on the surface, e.g. $\mathrm{OH}_{\mathrm{ads}} .{ }^{25}$ At the same time, the peak current density of ORR was also increased on the $\mathrm{Pt} / \mathrm{GC}$ electrodes compared with that of the commercial Pt/C electrode. A maximum of the peak current density also appeared on the $\mathrm{Pt} / \mathrm{GC}$ catalyst prepared under $-0.15 \mathrm{~V}$. It is worth noting that although the $\mathrm{Pt} / \mathrm{GC}$ catalyst prepared under $-0.15 \mathrm{~V}$ had a lower ECSA than that at $-0.06 \mathrm{~V}$, its ORR activity was the highest according to the ORR potential and current density.

In order to obtain additional information on the ORR, the EIS characteristics of the electrodes, whose catalyst layers were deposited at different potentials, were investigated in $0.1 \mathrm{M}$ $\mathrm{HClO}_{4}$ under a saturated $\mathrm{O}_{2}$ atmosphere. The corresponding plots are shown in Fig. 4. All the EIS presented a large semicircle in the Nyquist diagram, but the arc diameters were different. The wide phase angle in the Bode diagram shown in Fig. 4(c) suggests that there are at least two time constants in each EIS curve, corresponding to one capacitive arc on the Nyquist spectrum in the high-frequency domain and the other in the low-frequency domain. ${ }^{26}$ These two capacitive arcs overlap together and thus, only one large semicircle appears in the Nyquist diagram. At high frequencies, the capacitive arc is a gauge of the charge transfer.

Resistance, relating to the charge transfer reaction kinetics ${ }^{27,28}$ and contributing to the cathodic ORR processes; the second capacitive arc in the low-frequency region represents the mass transfer process, contributing to the diffusion of oxygen to the Pt active surfaces and the proton transfer resistance within the catalyst layers. The EIS data are always fitted using an equivalent circuit to gain more details on the ORR process. Based on the analysis above, the equivalent circuit $R(Q(R(Q R)))$ shown in Fig. 5 is more appropriate for all the Pt/GC electrodes and the fitted results are listed in Table 3 . The fitting accuracy was estimated using the chi-square value $\left(\chi^{2}\right)$, which was in the magnitude of $10^{-4}$ for all of the fitted data in this study, implying that this equivalent circuit is suitable to reflect the ORR process of the electrodes. In this equivalent circuit, $R_{\mathrm{S}}$ is the solution resistance, $Q_{\mathrm{f}}$ is the constant phase element $(\mathrm{CPE})$ of the deposited layer of Pt particles, $R_{\mathrm{f}}$ is the resistance of deposited layer, $Q_{\mathrm{ct}}$ is the constant phase element (CPE) of the electric double layer and $R_{\mathrm{ct}}$ is the charge transfer resistance for the ORR of the GC interface. Considering that the heterogeneity of the electrode surface could cause deviation in the electric double layer from pure capacitance, a constant phase angle element $Q$ was chosen to substitute the pure capacitance $C$. The impedance function of a CPE complies with the following equation:

$$
Z_{\mathrm{CPE}}=Y_{0}^{-1}(\mathrm{j} \omega)^{-n}
$$

where $Y_{0}$ is the CPE constant, $\omega$ is the angular frequency (in rad $\mathrm{s}^{-1}$ ), and $\mathrm{j}$ is the imaginary unit and $n$ a CPE exponent, which can be used as a gauge of the heterogeneity or roughness of the surface.

The ORR process is very complicated, including the charge transfer process, the mass transfer process, and the reactions on the catalyst. ${ }^{29}$ Therefore, enhancing the electron transfer 

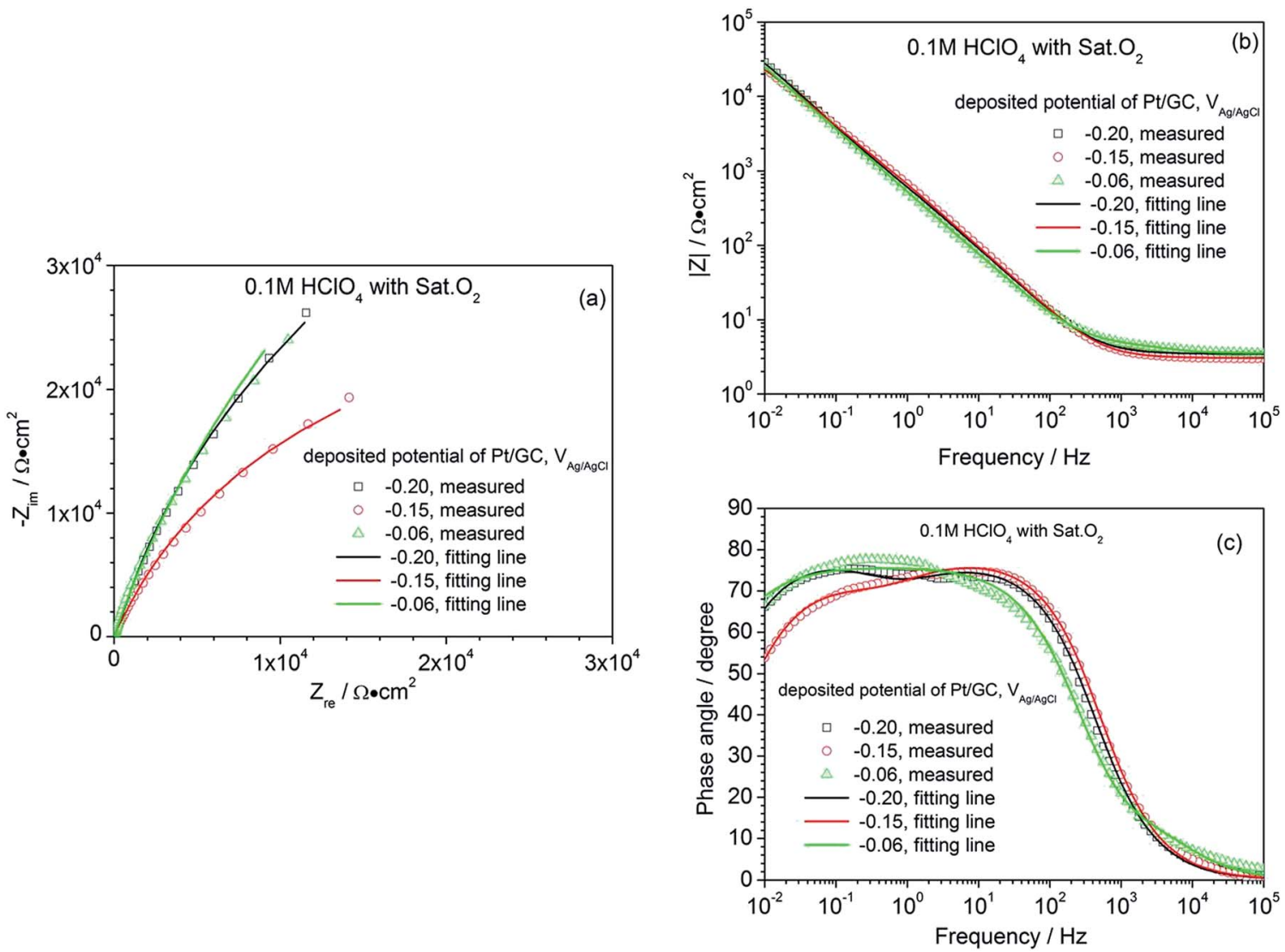

Fig. 4 Nyquist (a) and Bode (b, and c) diagram of a commercial Pt/C electrode and the as-prepared Pt/GC catalysts in $0.1 \mathrm{M} \mathrm{HClO} 4$ under a saturated $\mathrm{O}_{2}$ atmosphere.

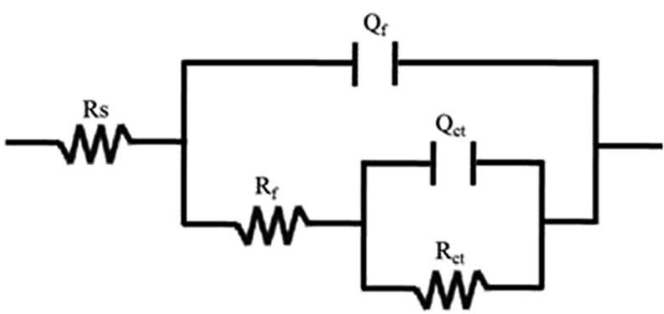

Fig. 5 The equivalent circuit used to fit the EIS.

ability by lowering the charge transfer resistance $R_{\mathrm{ct}}$ is an effective way to optimize an ORR catalyst. ${ }^{30} \mathrm{~A}$ lower $R_{\mathrm{ct}}$ value suggests the superior charge transfer ability during the ORR, which can facilitate the ORR process. As can be seen in Table 3 , the charge transfer resistance $R_{\mathrm{ct}}$ of the $\mathrm{Pt} / \mathrm{GC}$ electrode deposited at $-0.15 \mathrm{~V}$ has a minimum value of $0.58 \times 10^{5} \Omega \mathrm{cm}^{2}$, suggesting a fastest reaction rate for the ORR on this electrode. The results of EIS are in agreement with those found for the CV presented above.

\subsection{Surface characterization}

Fig. 6 presents the SEM images and EDS of the Pt particles electrodeposited on ITO. As can be seen, the surface morphology of the samples was strongly dependent on the deposition potentials. The Pt particle prepared under $-0.20 \mathrm{~V}$ exhibited cube shapes with several sharp corners (Fig. 6a1, high magnification), uniformly distributed (Fig. 6a2, low magnification) and displayed a grain size close to $100 \mathrm{~nm}$. These sharp corners maybe ascribed to the $\mathrm{Pt}(111)$ facet, which is the main face of the tetrahedral structures. It could be seen from the $i-t$ curves (shown in Fig. 1) that the current density deposited under $-0.20 \mathrm{~V}$ was the highest. It is reported ${ }^{31}$ that the

Table 3 The fitted results of the EIS of the Pt/GC electrodes deposited at different potentials

\begin{tabular}{|c|c|c|c|c|c|c|c|}
\hline Deposited potential/V & $R_{\mathrm{s}} / \Omega \mathrm{cm}^{2}$ & $Q_{\mathrm{f}}-Y_{0} / 10^{-4} \mathrm{~F} \mathrm{~cm}^{-2}$ & $n$ & $R_{\mathrm{f}} / 10^{3} \Omega \mathrm{cm}^{2}$ & $Q_{\mathrm{ct}}-Y_{0} / 10^{-4} \mathrm{~F} \mathrm{~cm}^{-2}$ & $n$ & $R_{\mathrm{ct}} / 10^{5} \Omega \mathrm{cm}^{2}$ \\
\hline-0.20 & 3.45 & 1.62 & 0.83 & 0.16 & 3.78 & 0.88 & 1.23 \\
\hline-0.15 & 3.06 & 2.84 & 0.87 & 4.30 & 1.04 & 0.74 & 0.58 \\
\hline
\end{tabular}



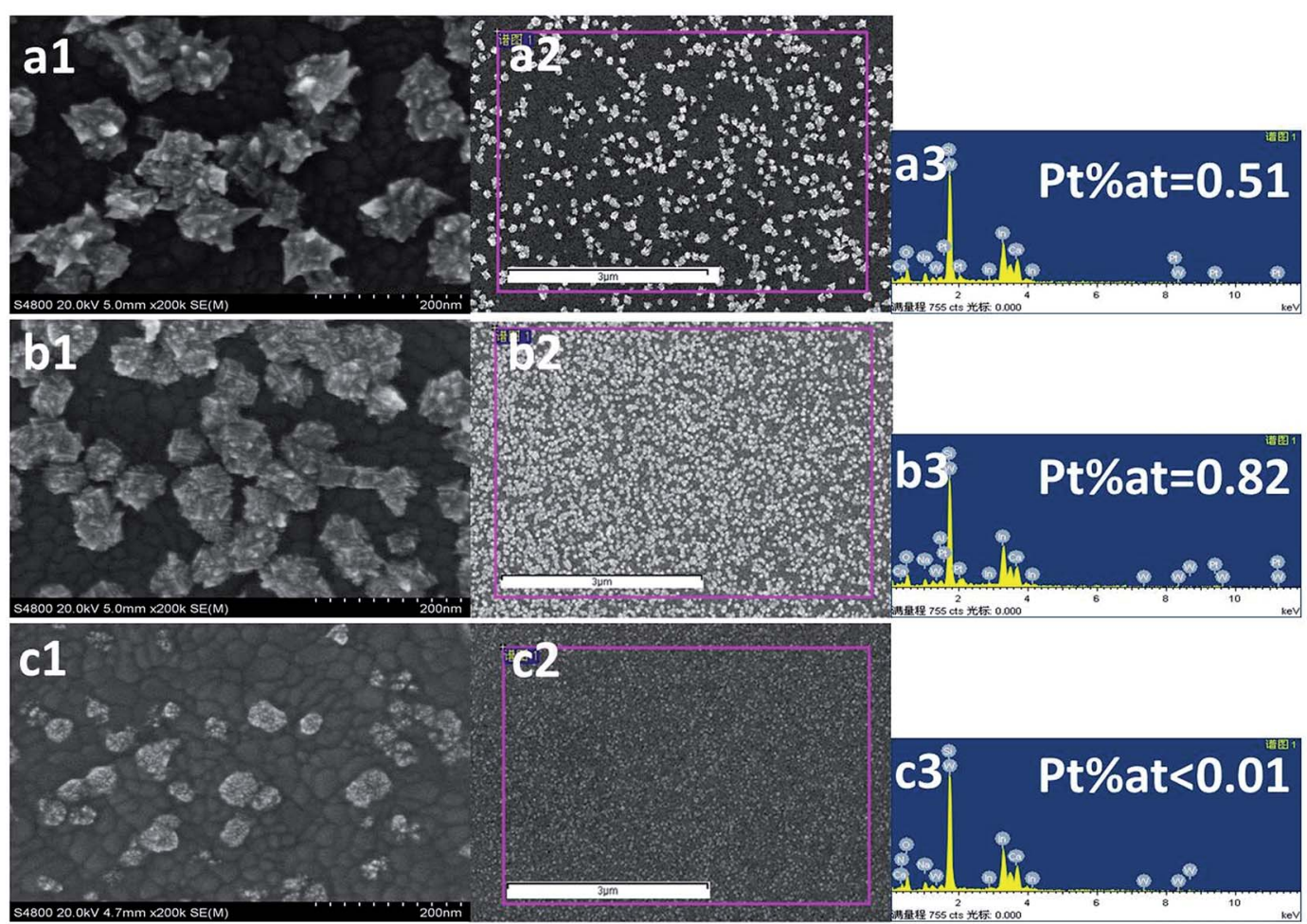

Fig. 6 The SEM images and EDS of the Pt/ITO prepared at different deposited potentials: $-0.20 \mathrm{~V}(\mathrm{a} 1, \mathrm{a} 2 \mathrm{and}$ a3), $-0.15 \mathrm{~V}$ (b1, b2 and b3), $-0.06 \mathrm{~V}$ (c1, c2 and c3).

nucleation rate of electrodeposition can be promoted at a high applied current density, causing the formation of small grainsized particles and fine crystal structure. Nevertheless, if the applied current density is high enough to make the electrodeposition proceed under (or closer to) mass transfer control, large and coarse metal particles are formed. ${ }^{17,32}$ Accordingly, the current density under a deposition potential of $-0.20 \mathrm{~V}$ may be so high that the electrodeposition is under mass transfer control and thus, produces coarse particles. When deposited at $-0.15 \mathrm{~V}$, the distribution of Pt particles became more uniform, and the particle size was smaller and appeared as regular cubes without sharp corners (Fig. 6b1). At the same time, the distribution density of the Pt particles increased under this deposition potential compared to that under $-0.20 \mathrm{~V}$ (Fig. 6b2), resulting in an increase in the Pt atom percentage rising from 0.51 (Fig. 6a3) to 0.82 (Fig. 6b3). The specific areas of the EDS analysis are those in the red frames shown in Fig. 6a2, b2 and c2 for the catalysts obtained at $-0.20 \mathrm{~V},-0.15 \mathrm{~V}$ and $-0.06 \mathrm{~V}$, respectively. Because the magnification in Fig. 6a2, b2 and c2 was 21000 , each area in the red frames was about $30 \mu \mathrm{m}^{2}$, which is much greater than the diameter of the beam (in $\mathrm{nm}$ ) in EDS and thus, the EDS data is credible for qualitative analysis.

It is noticeable that at an equal applied charge density, the amount of catalyst loading obtained at the lower current density (corresponding to the deposition potential of $-0.15 \mathrm{~V}$ ) tends to be higher than that obtained at the higher current density (corresponding to the deposited potential of $-0.20 \mathrm{~V}$ ). This may be ascribed to the intense hydrogen evolution and low current efficiency caused by the higher current density. ${ }^{33}$ When deposition was carried out under $-0.60 \mathrm{~V}$, the Pt particles became equiaxed crystals with a much smaller particle size, less than $50 \mathrm{~nm}$ (Fig. 6c1). It has been demonstrated that the shape of the particles has a great influence on its catalytic efficiency. Particles with multipods exhibit better catalytic activity than spherical ones due to the presence of rich active edges/corner atoms. ${ }^{34}$ Accordingly, the low catalytic activity of the Pt/GC electrode deposited at $-0.06 \mathrm{~V}$ with equiaxed crystals is reasonable, considering its lower number of active sites. Moreover, the distribution of the particles (Fig. 6c2) was not uniform and the deposited amount decreased sharply, which was not detectable using the EDS technique (Fig. 6c3).

Fig. 7 shows the XRD patterns of the electrodeposited Pt catalysts on ITO (a) and the partially enlarged region (b). All the strong peaks in the obtained XRD patterns originate from the ITO background $\left(\operatorname{In}_{2} \mathrm{O}_{3}(222)\right.$ and $\left.\operatorname{In}_{2} \mathrm{O}_{3}(400)\right)$ because of the small loading amount of the electrodeposited Pt catalysts. Significantly, there were weak peaks originating from the deposited Pt particles in the high region of the Pt/ITO XRD patterns, which did not exist in the naked ITO. In the XRD pattern deposited under $-0.20 \mathrm{~V}$, a peak located at around $40^{\circ}$ appeared, corresponding to the crystallographic planes of $\operatorname{Pt}(111)$, while under -0.15 and $-0.06 \mathrm{~V}$ a peak emerged at around $46^{\circ}$, indicating the existence of the crystallographic planes $\mathrm{Pt}(200)$. Since the crystal structure of Pt metal belongs to cubic systems, its lattice parameters can be calculated using the following equation: ${ }^{35}$ 

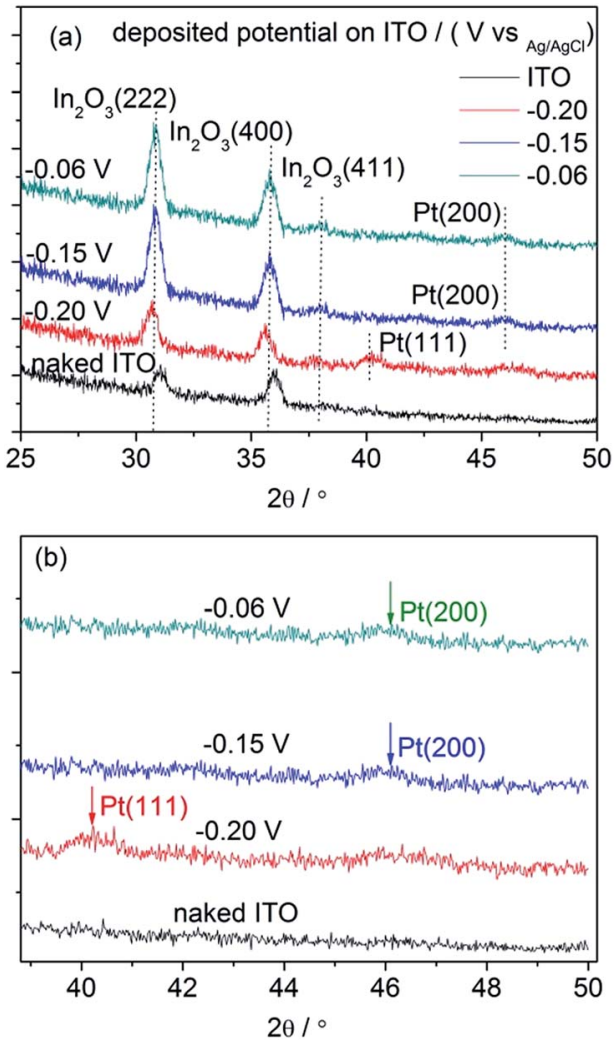

Fig. 7 The XRD patterns obtained for the Pt/ITO catalyst grown on ITO and background ITO (a), the partial enlarged region (b).

Table 4 The calculated results of the lattice parameters of the Pt/GC catalysts deposited at different potentials

\begin{tabular}{lllll}
\hline Deposited potential/V & $(h k l)$ & $2 \theta /^{\circ}$ & $\sin \theta$ & $a / \AA$ \\
\hline-0.20 & $(111)$ & 40.25 & 0.3441 & 3.8776 \\
-0.15 & $(200)$ & 45.90 & 0.3899 & 3.9510 \\
-0.06 & $(200)$ & 45.85 & 0.3895 & 3.9551 \\
\hline
\end{tabular}

$$
\frac{4 \sin ^{2} \theta}{\lambda^{2}}=\frac{h^{2}+k^{2}+l^{2}}{a^{2}}
$$

where $\lambda$ is the wavelength of the $\mathrm{X}$-rays used ( $\mathrm{K} \alpha 1$ of $\mathrm{Cu}$ target, $1.5406 \AA$ ), $\theta$ is the angle between incident X-ray and the corresponding crystal face, $h, k$ and $l$ are the Miller indices and $a$ is the lattice parameter of the Pt catalyst. The calculated results for the lattice parameters are listed in Table 4 . It can be seen that the values of $a$ were different from each other and all deviated slightly from the standard value (3.924 ̊).

It has been demonstrated that nanoparticles with high-index planes have higher activity than (111) or (100), ${ }^{36,37}$ including tetrahexahedron $(h k 0)$, trapezohedron $(h k k)$ and trisoctahedron $(h h k)$ with at least one Miller index being larger than unity. This activity enhancement in the high-index planes was ascribed to the high density of the low-coordinated atoms situated on the steps, ledges and kinks. ${ }^{38,39}$ The ORR activities were highly dependent on the orientation of the steps and terraces on the surfaces. Accordingly, it is reasonable that the ORR activity of the Pt catalyst was higher when deposited under $-0.15 \mathrm{~V}$ than that under $-0.20 \mathrm{~V}$. On the other hand, although the particle size of Pt deposited under $-0.06 \mathrm{~V}$ was smaller than that under $-0.15 \mathrm{~V}$ and also possessed the high-index planes, the equiaxed particle shape with less active sites limited the ORR activity of the catalyst. As mentioned above, the highest ECSA of Pt/GC under $-0.06 \mathrm{~V}$ did not definitely correspond to the highest ORR activity.

\section{Conclusions}

Pt catalysts were prepared on glassy carbon (GC) electrodes using a potentiostatic method under different deposition potentials. The electrode deposited at $-0.15 \mathrm{~V}$ exhibited the highest ORR activity with the existence of high-index planes and the shape effect of Pt. Neither too high nor too low potential is in favourable for the catalytic activity considering both the exposed planes and the shape of the Pt particles.

\section{Acknowledgements}

This study was supported by the National Natural Science Foundation of China (No. 21673267).

\section{References}

1 X. Zhou, J. Qiao, L. Yang and J. Zhang, Adv. Energy Mater., 2014, 4, 1301523.

2 J. K. Dombrovskis and A. E. C. Palmqvist, Fuel Cells, 2016, 16, 4.

3 Y. Wang, H. Luo, G. Li and J. Jiang, Appl. Energy, 2016, 173, 59.

4 Z. D. Wei, S. H. Chan, L. L. Li, H. F. Cai, Z. T. Xia and C. X. Sun, Electrochim. Acta, 2005, 50, 2279.

5 J. Li, F. Ye, L. Chen, T. Wang, J. Li and X. Wang, J. Power Sources, 2009, 186, 320.

6 H. A. Gasteiger, S. S. Kocha, B. Sompalli and F. T. Wagner, Appl. Catal., B, 2005, 56, 9.

7 R. Borup, J. Meyers, B. Pivovar, Y. S. Kim, R. Mukundan, N. Garland, D. Myers, M. Wilson, F. Garzon and D. Wood, Chem. Rev., 2007, 107, 3904.

8 J. Liu, E. Li, M. Ruan, P. Song and W. Xu, Catalysts, 2015, 5, 1167.

9 S. Mukerjee and J. Mcbreen, J. Electroanal. Chem., 1998, 448, 163.

10 N. Markovic, H. Gasteiger and P. N. Ross, J. Electrochem. Soc., 1997, 144, 1591.

11 B. Geboes, J. Ustarroz, K. Sentosun, H. Vanrompay, A. Hubin, S. Bals and T. Breugelmans, ACS Catal., 2016, 6, 5856.

12 H. Kim, N. P. Subramanian and B. N. Popov, J. Power Sources, 2004, 138, 14.

13 J. Seo, D. Cha, K. Takanabe, J. Kubota and K. Domen, ACS Catal., 2013, 3, 2181.

14 S. B. Han, Int. J. Electrochem. Sci., 2016, 3803. 
15 J. Kaushik, T. D. Van Anh, V. Tiny, C. Serdar and F. A. de Bruijn, J. Phys. Chem. C, 2009, 113, 20371.

16 M. M. E. Duarte, A. S. Pilla, J. M. Sieben and C. E. Mayer, Electrochem. Commun., 2006, 8, 159.

17 Y. Saejeng and N. Tantavichet, J. Appl. Electrochem., 2008, 39, 123.

18 Y. B. Cho, C. Lee and Y. Lee, J. Electrochem. Soc., 2015, 162, H792.

19 N. Doan, T. Sundqvist, P. Hiekkataipale, J. Korhonen, T. Kallio, J. Ruokolainen, K. Kontturi and C. Johans, Int. J. Electrochem. Sci., 2015, 10, 2535.

20 Z. Awaludin, J. G. Sheng Moo, T. Okajima and T. Ohsaka, J. Mater. Chem. A, 2013, 1, 14754.

21 Y. Garsany, O. A. Baturina, K. E. Swider-Lyons and S. S. Kocha, Anal. Chem., 2010, 82, 6321.

22 K. Shimazu, D. Weisshaar and T. Kuwana, J. Electroanal. Chem., 1987, 223, 223.

23 F. Gloaguen, J. M. Léger and C. Lamy, J. Appl. Electrochem., 1997, 27, 1052.

24 F. Takasaki, S. Matsuie, Y. Takabatake, Z. Noda, A. Hayashi, Y. Shiratori, K. Ito and K. Sasaki, J. Electrochem. Soc., 2011, 158, B1270.

25 Z. M. Zhou, Z. G. Shao, X. P. Qin, X. G. Chen, Z. D. We and B. L. Yi, Int. J. Hydrogen Energy, 2010, 35, 1719.

26 J. Zhang, Y. Tang, C. Song and J. Zhang, J. Power Sources, 2007, 172, 163.
27 S. D. Yang, C. M. Shen, X. J. Lu, H. Tong, J. J. Zhu, X. G. Zhang and H. J. Gao, Electrochim. Acta, 2012, 62, 242.

28 X. Cui, S. N. Wu, S. Jungwirth, Z. B. Chen, Z. H. Wang, L. Wang and Y. X. Li, Nanotechnology, 2013, 24, 765-771.

29 K. Gong, F. Du, Z. Xia, M. Durstock and L. Dai, Science, 2009, 323, 760.

30 L. Li, P. Dai, X. Gu, Y. Wang, L. Yan and X. Zhao, J. Mater. Chem. A, 2017, 5, 789.

31 M. J. Amstrong and R. H. Muller, J. Electrochem. Soc., 1991, 138, 2303.

32 O. Chène and D. Landolt, J. Appl. Electrochem., 1989, 19, 188.

33 C. Rao and D. Trivedi, Coord. Chem. Rev., 2005, 249, 613.

34 D. Chen, P. Sun, H. Liu and J. Yang, J. Mater. Chem. A, 2017, 5, 4421, DOI: 10.1039/c6ta10476b.

35 Y. Waseda, E. Matsubara and K. Shinoda, X-Ray diffraction crystallography, Springer, Heidelberg, Dordrecht, London, NewYork, 2011, ch. 4, p. 115, DOI: 10.1007/978-3-64216635-8.

36 K. Sasaki, H. Naohara, Y. Cai, Y. M. Choi, P. Liu, M. B. Vukmirovic, J. X. Wang and R. R. Adzic, Angew. Chem., Int. Ed., 2010, 49, 8602.

37 A. Kuzume, E. Herrero and J. M. Feliu, J. Electroanal. Chem., 2007, 599, 333.

38 A. M. Gómez-Marín and J. M. Feliu, Catal. Today, 2015, 244, 172.

39 Q. S. Chen, F. J. Vidal-Iglesias, J. Solla-Gullon, S. G. Sun and J. M. Feliu, Chem. Sci., 2012, 3, 136. 